\title{
Formação Acadêmica em Educação Física: perfis profissionais, objetivos e fluxos curriculares
}

\author{
Dagmar Aparecida Cynthia França Hunger ${ }^{12}$ \\ Fernanda Rossi ${ }^{2} 3$ \\ ${ }^{1}$ Faculdade de Ciências. UNESP - Univ Estadual Paulista, Campus de Bauru, \\ Departamento de Educação Física, ESCHEF, Bauru, SP, Brasil \\ 2 Instituto de Biociências, UNESP - Univ Estadual Paulista, Campus Rio Claro, \\ Departamento de Educação Física, NEPEF, UNESP Rio Claro, SP, Brasil \\ ${ }^{3}$ Mestranda do Programa de Pós-Graduação em Ciências da Motricidade, UNESP Rio \\ Claro, SP, Brasil e Bolsista do CNPq
}

\begin{abstract}
Resumo: Na presente pesquisa, de natureza qualitativa, objetivou analisar os Perfis Profissionais, Objetivos e Fluxos Curriculares especificados nos Projetos Pedagógicos dos Cursos de Graduação, na área de Educação Física, das Universidades Públicas Estaduais e Federais do Estado de São Paulo, bem como, averiguar suas articulações e adequações ao Projeto Pedagógico Institucional e Plano de Desenvolvimento Institucional. Abordamos as últimas Resoluções da Educação Física no Ensino Superior e conceituações de Projeto Pedagógico de Curso. O método de abordagem é a história do tempo presente. Realizamos pesquisa documental, analisando documentos oficiais. Constatamos limitada oferta de cursos públicos quando comparada as instituições privadas; maior oferta de cursos de bacharelado (formação ampliada e generalizada) nos campos da saúde, do esporte e lazer; cursos definidos especificamente para a formação de professores escolares e descompasso entre os discursos pedagógicos e as estruturas curriculares. Concluímos necessária mudança de mentalidade curricular para se concretizar os discursos pedagógicos dos Cursos.
\end{abstract}

Palavras-chave: Formação Acadêmica Inicial. Projeto Pedagógico de Curso. Educação Física.

\section{Professional Formation in Physical Education: job profiles, objectives and curriculum flows}

\begin{abstract}
In this research, characterized as a qualitative study, we aimed to analyze the Job Profiles, Objectives and Curriculum Flows specified in Pedagogical Projects of the undergraduate Courses of Physical Education of public, state and federal universities, in the São Paulo state. We also analyzed their articulations and adequacy to the Institutional Pedagogical Project and Institutional Development Plan. The latest Resolutions of Physical Education in Higher Education and conceptualizations of the Pedagogical Project of Course are presented. The method of approach is current History. There was a documental research in order to analyze the official documents. A limited offering of public courses when compared to private institutions was verified and also, there was a greater offering of bachelor degree courses (expanded and generalized formation) concerning health, sport and leisure fields. Courses defined specifically for teachers' formation and educational gap between the pedagogical discourses and the curriculum structures were also presented. In conclusion, this research indicates the necessity of a change in the curricular mentality in order to implement the pedagogical discourses of courses.
\end{abstract}

Key Words: Initial Professional Formation. Pedagogical Project of Course. Physical Education.

\section{Introdução}

No início do século XXI, o Conselho Nacional de Educação publica novos Pareceres, Resoluções e Diretrizes Nacionais para a Educação Superior. No que diz respeito, especificamente, aos Cursos de Graduação em Educação Física, estes deveriam adequar-se as Diretrizes Curriculares Nacionais para formação de professores de educação básica, em nível superior, curso de licenciatura, de graduação plena (Parecer CP n'. 9/2001); Parecer CNE/CP $\underline{n^{\circ} .27}$, de 2 de outubro de 2001; Parecer CNE/CP $\mathrm{n}^{\circ}$. 28, de 2 de outubro de 2001; Resolução CNE/CP no. 1, de 18 de fevereiro de 2002 e Resolução CNE/CP n ${ }^{\circ}$. 2, de 19 de fevereiro de 2002; bem como adequar-se ao Parecer CNE/CSE no. 58, de 18 de fevereiro 2004 e à Resolução CNE/CSE no. 7, de 31 de março de 2004 que institui as diretrizes curriculares para os cursos de graduação (bacharelado) em Educação Física.

Assim sendo, as novas propostas de Cursos de Graduação em Educação Física, bem como, os Cursos já existentes, obrigatoriamente, são implantados ou reestruturados devendo 
responder e/ou adequar-se as novas exigências da legislação vigente. Se a década final do século XX foi marcante para a Educação Física, em decorrência do reconhecimento como profissional da área de saúde (Resolução n. 218/CNS/1997); da regulamentação da profissão em Educação Física (Lei no. 9.696/1998) e, conseqüente criação do sistema CONFEF/CREF, bem como, da promulgação da nova LDB (Lei n . 9.394/96 trata-se da obrigatoriedade do Projeto Pedagógico, especificada também na legislação do CEE - Conselho Estadual de Educação Deliberação $n^{\circ}$. 7/2000), no início do século XXI tem-se além das normativas acima citadas, 0 status profissional da Educação Física garantido com a sua inserção na Classificação Brasileira de Ocupações (2002).

Considerando-se a conjectura atual, avaliamos pertinente no presente estudo analisar os Perfis Profissionais, Objetivos e Fluxos Curriculares especificados nos Cursos de Educação Física, da Educação Superior, das Universidades Públicas Estaduais (UNESP, USP, UNICAMP) e Federais (UFSCar, UNIFESP) do Estado de São Paulo. Uma análise em que objetivamos, também, averiguar as articulações dos itens acima mencionados, bem como, suas adequações ao Projeto Pedagógico Institucional (PPI) e Plano de Desenvolvimento Institucional (PDI), conforme as orientações dos instrumentos do Sistema Nacional de Avaliação da Educação Superior (SINAES). Enfim, evidenciar as configurações da formação universitária inicial na área da Educação Física, em Instituições Públicas Estaduais e Federais do Estado de São Paulo, as quais priorizam o ensino, a pesquisa e a extensão, ou melhor, o princípio indissociável no exercício acadêmico do docente-pesquisador.

\section{Legislação dos Cursos de Graduação em Educação Física}

Na Resolução $n^{\circ}$ 7, de 31 de março de 2004 (CNE/CES), a Educação Física é definida como uma área de conhecimento e intervenção acadêmico-profissional. O movimento humano configura-se como o objeto de estudo e de aplicação, abrangendo os seguintes conteúdos: exercício físico, ginástica, jogo, esporte, luta/arte marcial e dança.

No que se refere às perspectivas profissionais constata-se uma gama de opções em termos de atuação no campo de trabalho voltadas para a prevenção, promoção, proteção e reabilitação da saúde, da formação cultural, da educação e da reeducação motora, do rendimento físicoesportivo, do lazer, da gestão de empreendimentos relacionados às atividades físicas, recreativas e esportivas etc.

As competências e habilidades formadas focalizam o profissional para atuar nos campos das políticas públicas e institucionais, da saúde, do lazer, do esporte, da educação, da segurança, do urbanismo, do ambiente, da cultura, do trabalho etc. Profissionais são habilitados para diagnosticar os interesses, as expectativas e as necessidades de grupos sociais e aplicar programas de atividades físicas, recreativas e esportivas; analisar as técnicas, instrumentos, equipamentos, procedimentos e metodologias para a produção e a intervenção acadêmicoprofissional; acompanhar as transformações acadêmico-científicas da Educação Física e de áreas afins e, enfim, utilizar recursos da tecnologia da informação e comunicação com o intuito de ampliar e diversificar interações com as fontes de produção e de difusão de conhecimentos específicos da Educação Física e de áreas afins, visando contínua atualização e produção acadêmico-profissional.

Advogam-se como concepções de formação profissional: a generalista, a humanista e a crítica da realidade social; pautadas no conhecimento acadêmico e científico, na reflexão filosófica e na conduta ética, a qual qualificará o profissional para sua intervenção. Objetiva-se formação, ampliação e enriquecimento cultural das pessoas, destacando-se a adoção de um estilo de vida fisicamente ativo e saudável.

O projeto pedagógico de curso é definido como construção e gestão coletiva, o qual deve abranger os princípios da autonomia institucional; articulação entre ensino, pesquisa e extensão; graduação como formação inicial; formação continuada; ética pessoal e profissional; ação crítica, investigativa e reconstrutiva do conhecimento; abordagem interdisciplinar do conhecimento; indissociabilidade teoria-prática, por meio da prática como componente curricular, estágio profissional curricular supervisionado e atividades complementares; articulação entre conhecimentos de formação ampliada e específica. As competências de natureza políticosocial, ético-moral, técnico-profissional e científica, definidas como concepção nuclear do processo da formação, devem propiciar domínio dos conhecimentos conceituais, procedimentais e atitudinais específicos da área e aqueles advindos das ciências afins, orientados por valores sociais, morais, éticos e estéticos de acordo com uma sociedade de caráter plural e democrática. 
Assim, o ensino de graduação deve abordar questões pertinentes às peculiaridades regionais, às identidades culturais, à educação ambiental, ao trabalho, às necessidades das pessoas portadoras de deficiência e de comunidades especiais.

A formação ampliada do curso refere-se aos conhecimentos da relação homem e sociedade; biológicos; produção do conhecimento científico e tecnológico. A formação específica, ou seja, os conhecimentos identificadores da área contemplam as dimensões culturais do movimento humano; a técnico-instrumental e a didático-pedagógica.

\section{O projeto pedagógico do curso poderá propor um ou mais núcleos temáticos de aprofundamento, utilizando até $20 \%$ da carga horária total, articulando as unidades de conhecimento e de experiências definidas. Deve, ainda, disponibilizar $40 \%$ da carga horária do estágio profissional curricular supervisionado para o campo da intervenção.}

A prática como componente curricular, prevista desde o início do curso, deverá estar presente no processo de formação acadêmica, sendo vivenciada por alunos nos diversos contextos sociais de aplicação acadêmicoprofissional. E, o estágio profissional curricular significa ao graduando, a partir da segunda metade do curso, possibilidades de vivência e consolidação das competências referentes ao exercício acadêmico-profissional em campos de intervenção da área, sob a supervisão de um profissional.

As atividades complementares incrementadas no percurso do curso têm como papel o aprimoramento do conhecimento e fornecer experiências para o graduando, por intermédio de estudos e práticas independentes, presenciais e/ou à distância, realizando monitorias, estágios extracurriculares e participando de programas de iniciação científica, programas de extensão, estudos complementares, congressos, seminários e cursos.

Para a integralização da formação acadêmica poderá ser exigida a apresentação de um trabalho de conclusão, sob a orientação de um docente-pesquisador.

A avaliação curricular compõe o domínio dos conteúdos e das experiências, preocupada com a qualidade da formação acadêmico-profissional e, respectivas competências político-sociais, éticomorais, técnico-profissionais e científicas. A avaliação do projeto pedagógico do curso deverá estar em consonância com o sistema de avaliação e o contexto curricular adotados pela instituição acadêmica.

Em suma, abordamos as diretrizes curriculares referentes à formação do profissional de Educação Física, em que as instituições de ensino superior devem obedecer.

Os cursos de Licenciatura Plena em Educação Física devem, ainda, obedecer ao estabelecido no Parecer CNE/CP n. 9/2001, no qual são abordadas especificamente questões referentes à formação de professores, priorizando-se a competência como núcleo orientador, bem como, destacando a necessidade de uma formação articulada com a atuação profissional e a pesquisa; à Resolução CNE/CP $n^{\circ}$. 1, destacando no Art. $6^{\circ}$ que

$\mathrm{Na}$ construção do projeto pedagógico dos cursos de formação dos docentes, serão consideradas:

I - as competências referentes ao comprometimento com os valores inspiradores da sociedade democrática;

II - as competências referentes à compreensão do papel social da escola;

III - as competências referentes ao domínio dos conteúdos a serem socializados, aos seus significados em diferentes contextos e sua articulação interdisciplinar;

IV - as competências referentes ao domínio do conhecimento pedagógico;

$\mathrm{V}$ - as competências referentes ao conhecimento de processos de investigação que possibilitem o aperfeiçoamento da prática pedagógica;

$\mathrm{VI}$ - as competências referentes ao gerenciamento do próprio desenvolvimento profissional (p. 2).

$\mathrm{E}$, à Resolução CNE/CP $\mathrm{n}^{\circ}$. 2, de 19 de fevereiro de 2002, na qual se institui a duração e a carga horária dos cursos de licenciatura, de graduação plena, de formação de professores da Educação Básica em nível superior, deliberando nos artigos $1^{\circ}$ e $2^{\circ}$ a carga horária de, no mínimo, 2800 (duas mil e oitocentas) horas, integralizadas em, no mínimo, 3 (três) anos letivos, obedecidos os 200 (duzentos) dias letivos/ano, nas quais a articulação teoria-prática deve garantir, nos termos dos projetos pedagógicos, as seguintes dimensões dos componentes comuns: 400 (quatrocentas) horas de prática como componente curricular, vivenciadas ao longo do curso; 400 (quatrocentas) horas de estágio curricular supervisionado a partir do início da segunda metade do curso; 1800 (mil e oitocentas) horas de aulas para os conteúdos curriculares de natureza científico-cultural; 200 (duzentas) horas para outras formas de atividades acadêmicocientífico-culturais.

Além da Docência Escolar em Educação Física, as especificidades da intervenção profissional compreendem o Treinamento 
Desportivo, a Preparação Física, a Avaliação Física, a Recreação em Atividade Física, a Orientação de Atividades Físicas e Gestão em Educação Física e Desporto.

\section{Conceituações de Projeto Pedagógico de Curso}

A obrigatoriedade do Projeto Pedagógico está definida na LDB (Lei n ${ }^{\circ}$ 9394/96) e na legislação do CEE - Conselho Estadual de Educação Deliberação $n^{\circ}$. 07/2000, a qual dispõe sobre a autorização para funcionamento e reconhecimento de cursos e habilitações novos, oferecidos por Instituição de Ensino Superior. Conforme o disposto no Art. $4^{\circ}$, o Projeto Pedagógico de curso deve conter:

- Perfil do Profissional a ser formado;

- Objetivos Gerais e Específicos do curso;

- Descrição do Currículo Pleno oferecido, com ementário das disciplinas/atividades (o currículo deve explicitar a adequação da organização pedagógica ao perfil profissional definido);

- Bibliografia Básica;

- Número de vagas iniciais e turno de funcionamento;

- Relação dos docentes e especificação da composição por níveis $\left(\mathrm{N}^{\mathrm{O}}\right.$ e $\%$ de Doutores, Mestres, etc);

- Acervo da Biblioteca (livros e periódicos especializados);

- Apresentação das instalações, equipamentos, laboratórios (no caso de reconhecimento, pode ser citado apenas as alterações e/ou ampliações feitas nas estruturas).

De acordo com Gadotti (2000) projetar significa lançar-se para frente, indica a idéia de um futuro diferente da situação do presente. Logo, o termo projeto pressupõe uma ação intencionada que traz consigo um sentido definido do que se quer inovar. Pereira (2008) corrobora com essa idéia ao destacar que os termos Projeto Pedagógico (PP - entende-se que o qualificativo político já está inserido) ou Projeto Político Pedagógico (PPP) designam o sentido de "projetar, de lançar, de orientar, de dar direção a uma idéia, a um processo pedagógico intencional alicerçado nas reflexões e ações do presente" ( $p$. $1)$.

O PP caracteriza-se como um instrumento teórico-metodológico que, por meio de uma leitura da realidade, visa intervir nessa realidade e transformá-la. Sua sistematização não é definitiva, podendo ser reconstruída ao longo de seu desenvolvimento (VASCONCELLOS, 2004a). Sem esquecer, ressalta Gadotti (2000, 2001), que um projeto necessita sempre rever o que está instituído para então instituir a mudança.

Para Vasconcellos (2004a, 2004b) o PP é o plano global da instituição. Consiste em um processo de planejamento participativo, que no seu decorrer se aperfeiçoa e se concretiza. Pereira (2008) ressalta que a sua elaboração exige uma reflexão acerca da concepção de educação e sua relação com a sociedade, bem como que tipo de indivíduo se busca formar. Sendo fruto de reflexão e investigação, como também nos indica Veiga (2003), o PP aponta um rumo, uma direção para um compromisso estabelecido coletivamente.

Pereira (2008) explicita que o PP é um instrumento balizador referente ao cotidiano universitário, o qual "expressa à prática pedagógica das instituições e dos cursos dando direção à gestão e às atividades educacionais" ( $p$. 1), representa a contínua expressão das idéias sobre a educação superior, por meio da reflexão sobre a universidade e sua função social.

O PP é a identidade da Instituição Universitária e do Curso, devendo originar-se de uma construção participativa e colaborativa (PADILHA, 2003; VASCONCELLOS, 2004a, 2004b; PEREIRA, 2008). Portanto, sua elaboração deve resultar da participação coletiva dos docentes, discentes e técnicoadministrativos. "É a configuração da singularidade e da particularidade da instituição educativa" (VEIGA, 2000, p. 187, citada por PEREIRA, 2008). Ou ainda, estabelece-se a priori que não deve se tratar de um procedimento isolado, desarticulado, descontextualizado, mas, especialmente, formativo. Alerta-se que 0 problema maior é justamente tal afirmação, pois a elaboração do PP exige processos complexos, complementares e integradores, bem como, necessita de especialistas no assunto. Pois, comporta dimensões filosóficas, políticas, sócioculturais, éticas e estruturais. E, principalmente, requer articulação com o projeto filosófico e político de Educação Superior da Instituição Universitária, isto é, necessita da discussão prévia da Instituição desejada.

\section{De acordo com Pereira (2008, p. 2):}

[...] o PP é construído no contexto de uma realidade complexa e sua estruturação revela as características das inter-relações existentes na instituição, nos cursos e entre cursos, no sistema educacional superior e no contexto social do qual faz parte. As possibilidades e os limites do PP passam por questões do contexto externo e da natureza interna da instituição. 
A lógica do PP não é independente da lógica institucional universitária e da sociedade. E, nesse sentido, pontuam-se princípios a se respeitar na sua construção, caracterizada como participativa e resultante de um esforço coletivo de conhecimento, interpretação e negociações; em consonância com uma avaliação pedagógica, social, organizada e intencionalmente orientada para soluções e transformações, a qual só se legitima quando fruto de um processo de debate crítico: a) definição conceitual em termos filosóficos, seus princípios, objetivos e suas metas institucionais; b) discussão ampla; construída e deliberada coletivamente; c) visão contextualizada que compreenda, interprete e explique as causas, conseqüências, contextos e os processos de ensino, pesquisa, extensão, gestão e infra-estrutura de modo integrado. ${ }^{1}$ Acreditamos que o PP origina de um processo de avaliação e assim, concordando com Sobrinho (2000), a avaliação da educação superior deve ser composta por várias avaliações, constituída de um conjunto articulado. Conforme suas palavras: "Não se pode reduzir todo o processo de avaliação a uma concepção unívoca e simplificadora" (p. 164). E, ainda, "não se pode adotar uma avaliação que, por exemplo, não contemple as distinções e características específicas das instituições, dos grupos humanos, dos contextos históricos etc." (p. 173). $\mathrm{E}$, principalmente, deve-se responder às seguintes questões: "Qual avaliação, para quem e para quê? Que universidade e para qual sociedade? Que tipo de profissional para qual mundo? Que conhecimentos e informações para qual formação?" (p. 157-8).

Questionamentos, também, presentes na construção do PP e que exigem reflexões das concepções e finalidades da educação e sua articulação com a sociedade e, ainda, uma discussão aprofundada sobre o cidadão a formar e o mundo que desejamos coconstruir. Complementando e/ou enfatizando, de acordo com Pereira (2008, p. 1):

O processo de construção de um PP pode ser desenvolvido através da tentativa de responder a várias questões:

- Qual é a concepção de homem e mundo que o PP trabalha?

- Qual a concepção de sociedade?

- Qual a concepção de educação?

- Qual a concepção de universidade?

\footnotetext{
1 Parágrafo elaborado conforme indicadores apresentados no livro intitulado "Avaliação da Educação Superior", de José Dias Sobrinho (2000, p. 193-8), Petrópolis, RJ: Vozes. O autor entende que a definição das principais características e condições de uma avaliação institucional é uma tarefa coletiva, a qual se concorda plenamente.
}

- Qual a concepção de cidadão?

- Qual a concepção de profissional?

- Qual a concepção de conhecimento?

- Qual a concepção de currículo?

- Qual é a relação teoria e prática?

Conforme o Instrumento de Avaliação de Cursos de Graduação (MEC, 2006), ao abordar a Concepção de Projeto Pedagógico de Curso (PPC) e sua articulação com Projeto Pedagógico Institucional (PPI), o Plano de Desenvolvimento Institucional (PDI) e o Currículo, afirma que ao se avaliar um curso é imprescindível considerar o PPI e o PDI, "tendo em vista a necessária sintonia entre PPC e os propósitos da instituição" (p. 7). E, ainda, advoga a importância do PPI, PDI, PPC e Currículo:

como documentos nos quais as IES explicitam seu posicionamento a respeito de sociedade, de educação e de ser humano e asseguram o cumprimento de suas políticas e ações. Os projetos, o plano e o currículo, muito mais que documentos técnico-burocráticos, consistem em instrumentos de ação política e pedagógica, cujo objetivo é promover uma formação com qualidade (p. 7).

\section{Concebe o currículo:}

como um espaço de formação plural, dinâmico e multicultural, fundamentado nos referenciais socioantropológicos, psicológicos, epistemológicos e pedagógicos em consonância com o perfil do egresso previsto nas Diretrizes Curriculares. Esses referenciais instituem 0 currículo como um conjunto de elementos que integram os processos de ensinar e de aprender num determinado tempo e contexto, garantindo a identidade do curso e o respeito à diversidade. É um dos elementos constitutivos do PPC, tendo como orientação básica as Diretrizes Curriculares Nacionais, cujo aperfeiçoamento implica a consideração dos resultados dos processos da avaliação. Desse documento de orientação acadêmica constam, dentre outros elementos: conhecimentos e saberes considerados necessários à formação das competências estabelecidas a partir do perfil do egresso; estrutura e conteúdo curricular; ementário; bibliografias básica e complementar; estratégias de ensino; docentes; recursos materiais; serviços administrativos; serviços de laboratórios; e infra-estrutura de apoio ao pleno funcionamento do curso (p. 7).

E, para avaliação do PPC apresenta os seguintes indicadores: 1.4.1 Coerência do currículo com os objetivos do curso; 1.4.2 Coerência do currículo com o perfil desejado do egresso; 1.4.3 Coerência do currículo face às diretrizes curriculares nacionais.

Finalizamos com o entendimento de Pimenta (2002, p. 110), de que:

A docência no Ensino Superior necessita de uma proposta coletiva e institucional, (que ao ser) assumida pelo coletivo docente, tem 
maiores possibilidades de produzir mudanças significativas do que ações individuais.

\section{Métodos}

A presente investigação caracterizou-se como uma pesquisa qualitativa, em que objetivamos compreender a problemática em questão considerando sua complexidade, atentando-se para a interferência do contexto e de variáveis que pudessem auxiliar em seu entendimento, a fim de interpretar o objeto de estudo.

De acordo com André (1995, p. 27), a pesquisa qualitativa caracteriza-se como aquela que se contrapõe "[...] ao esquema quantitativista de pesquisa $[\ldots] "$.

\section{E, conforme define Demo (1997, p. 84):}

Por maior que seja o esforço de preservar a face qualitativa dos fenômenos, o manejo científico deles implica formalização. Assim, não se trata - jamais - de desfazer a competência formal, mas de tomá-la com o devido espírito crítico, estabelecendo seu alcance e seu limite.

Fundamentamos a pesquisa conforme a abordagem da história do tempo presente. De acordo com Chartier (1996, p. 217),

a história do tempo presente [...], propicia uma reflexão essencial sobre as modalidades e mecanismos de incorporação do social pelos indivíduos que têm uma mesma formação ou configuração social.

\section{Técnicas de Pesquisa}

Pesquisa Bibliográfica (fontes secundárias periódicos, livros etc.): caracterizou-se em colocar as pesquisadoras em contato com o que já se produziu e registrou a respeito do assunto. Fundamentou a elaboração da revisão da literatura e subsidiou a discussão do problema.

Pesquisa Documental: como fontes primárias, analisamos os documentos oficiais referente à temática e ao problema em questão. Estudamos os Instrumentos de Avaliação, disponibilizados via internet, pelo Instituto Nacional de Estudos e Pesquisas Educacionais Anísio Teixeira (INEPSINAES). Analisamos os PPC (s), coletados por intermédio dos coordenadores dos Cursos investigados, disponibilizados via internet e/ou email, os quais não são identificados nos resultados e discussão, por definir na pesquisa como prioridade uma análise configuracional e não suas diferenciações, especificidades e particularidades.

Para tanto, consideramos o entendimento de Rampazzo (1998, p. 56), o qual diz que a análise documental se baseia "nos documentos de fonte primária, a saber, os 'dados primários". E, segundo Goody (s/d), citado por Le Goff (1992), o documento escrito é uma forma da memória coletiva que apresenta duas funções: a primeira resume-se no armazenamento de informações, fornecendo ao homem um processo de marcação, memorização e registro. A segunda, uma vez que o documento escrito é uma forma de registro, permite ao homem reexaminar, reordenar, retificar frases e até palavras isoladas. Mas, especialmente, conforme Le Goff (1992, p. 547), de que:

[...] o documento não é qualquer coisa que fica por conta do passado, é um produto da sociedade que o fabricou segundo as relações de forças que aí detinham o poder [...] e ainda, [...] é antes de mais nada o resultado de uma montagem, consciente ou inconsciente, da história, da época, da sociedade que o produziram, mas também das épocas sucessivas durante as quais continuou a viver, talvez esquecido, durante os quais continuou a ser manipulado, ainda que pelo silêncio.

$\mathrm{E}$, ainda, como um monumento:

[...] é em primeiro lugar uma roupagem, uma aparência enganadora, uma montagem. É preciso começar por desmontar, demolir esta montagem, desestruturar esta construção e analisar as condições de produção dos documentos - monumentos (LE GOFF, 1992, p. 547).

Por fim, consideramos como aponta Foucault (1969, p. 13), que os problemas da história podem ser resumidos numa só frase: "o questionar do documento". E, de acordo com Samaram (s/d), citado por Le Goff (1992): "Não há história sem documento" (p. 539).

\section{Amostra}

Refere-se aos Cursos de Graduação em Educação Física oferecidos nas Universidades Públicas Estaduais e Federais do Estado de São Paulo: Universidade do Estado de São Paulo (USP), Universidade Estadual Paulista (UNESP), Universidade Estadual de Campinas (UNICAMP), Universidade Federal de São Carlos (UFSCar), Universidade Federal de São Paulo (UNIFESP). O Instituto de Tecnologia da Aeronáutica (ITA) e a Universidade Federal do $A B C$ (UFABC) não oferecem Cursos de Educação Física.

Optamos por investigar Instituição de caráter administrativo Público (Estadual e Federal), dada sua responsabilidade social no cumprimento da educação, produção e disseminação dos conhecimentos culturais, científicos e tecnológicos. Ou ainda, a tríade ensino, pesquisa e extensão, segundo o princípio da indissociabilidade, são os pilares essenciais da Educação Superior Pública brasileira na formação do cidadão e re-construção da sociedade. 


\section{Resultados e Discussão}

Hoje, somente três Instituições Universitárias Públicas Estaduais e duas Federais oferecem Cursos de Educação Superior em Educação Física, portanto, totalizando apenas cinco Instituições Públicas no Estado de São Paulo. No quadro 1 abaixo compilamos as denominações dos Cursos das Instituições Públicas Estaduais e Federais, demonstrando as atuais tendências em termos de formação na área de Educação Física, no Estado de São Paulo, apresentando cursos distintos, voltados para a formação de professores escolares e/ou profissionais para atuarem, especialmente, nos campos da saúde, esporte e lazer. Observamos uma preocupação maior dos novos cursos voltados, especificamente, à saúde. No entanto, não obstante ao processo de espetacularização e profissionalização do Esporte Moderno, constatamos apenas um curso que trata somente do universo esportivo. Observação semelhante constatamos com relação às questões do lazer. Denotamos, ainda, uma tendência em caracterizar a formação do Graduando/Bacharel como generalista, ou seja, justamente um dos pontos críticos com referência aos cursos tradicionais de Licenciatura (formação ampliada e generalista).

\begin{tabular}{|l|c|c|}
\hline \multicolumn{1}{|c|}{ DENOMINAÇÃo Do CURSo } & $\begin{array}{c}\text { INSTITUIÇÃO PÚBLICA } \\
\text { ESTADUAL }\end{array}$ & $\begin{array}{c}\text { INSTITUIÇÃO } \\
\text { PÚBLICA FEDERAL }\end{array}$ \\
\hline Licenciatura em Educação Física & 4 & 1 \\
\hline $\begin{array}{l}\text { Licenciatura em Educação Física / Formação de } \\
\text { Professores em Educação Física (Licenciatura) }\end{array}$ & 1 & - \\
\hline Graduação (Bacharelado) em Educação Física & 1 & - \\
\hline $\begin{array}{l}\text { Graduação em Educação Física / Graduação em Educação } \\
\text { Física (Bacharelado) }\end{array}$ & 1 & - \\
\hline Bacharelado em Esporte & 1 & - \\
\hline Bacharelado em Educação Física & 1 & 1 \\
\hline $\begin{array}{l}\text { Educação Física - Modalidade Saúde / Bacharelado em } \\
\text { Educação Física - modalidade saúde * }\end{array}$ & - & - \\
\hline Bacharelado em Ciências da Atividade Física * & 1 & - \\
\hline Educação Física - Licenciatura e Bacharelado * & 1 & - \\
\hline Ciências do Esporte / Ciência do Esporte * & 1 & \\
\hline
\end{tabular}

* Cursos implantados recentemente, sem turmas formadas até o ano de 2008

Quadro 1. Total de Cursos Superiores oferecidos na área de Educação Física, por Instituições Públicas Estaduais e Federais, do Estado de São Paulo, de acordo com a denominação do Curso.

Se até o início da década de 80 configuravamse somente Cursos de Licenciatura, hoje, constatamos significativo aumento na oferta de Cursos de Graduação/Bacharelado (a Resolução $\underline{n^{\circ} 7}$, de 31 de março de 2004 (CNE / CES) adota a nomenclatura Graduação em Educação Física, em substituição ao termo Bachareladoº ${ }^{2}$. As Instituições investigadas apresentam projetos pedagógicos distintos para os chamados Cursos de Licenciatura e Bacharelado.

Ao consultarmos o site do Conselho Regional de Educação Física - 4a . Região (CREF 4/SP) surpreendeu a significativa diferença de número de Cursos de Educação Física oferecido por Instituições Privadas no Estado de São Paulo, ou seja, constatamos cadastrados, aproximadamente, 70 municípios e 130

\footnotetext{
2 O MEC está promovendo mudanças de nomes nos cursos de graduação da área da saúde com o objetivo de sistematizar as nomenclaturas que, frequentemente, são digitadas erradas ou têm nomes adicionais. Em novembro deste ano de 2009 será publicado o documento final com as alterações.
}

Instituições oferecendo cursos na área de Educação Física.

Não podemos deixar de registrar que se trata de um número irrisório de cursos ofertado pelas Instituições Estaduais ( 3 - 12 cursos) e Federais (2 - 2 cursos), em 9 municípios, quando comparado as Instituições Privadas que, habitualmente, disponibilizam em torno de 80 vagas por turma e, ainda, com a possibilidade do graduando obter as duas habilitações (Licenciatura e/ou Graduação/Bacharelado), sendo que as Públicas não ultrapassam, geralmente, 40 vagas por turma. Outro problema refere-se ao número mínimo de três anos letivos permitido para integralização de um curso de Licenciatura, o que passou a ser interessante em termos mercadológicos para as Instituições Privadas.

Sabemos que são nas Instituições Públicas onde se prioriza a pesquisa e, conseqüente produção e disseminação científica. Nesse 
sentido, há de se repensar a área. Se não se chega nem próximos ao número de 1.000 formandos por ano e poucos desenvolvem pesquisas e continuam na pós-graduação, o que se tem pesquisado, disseminado e aplicado de novo na área de Educação Física? Ou ainda, qual tem sido de fato o cumprimento do papel do profissional quando se pensa nos objetivos traçados nos Projetos Pedagógicos de Cursos, por exemplo, só com referência à transformação social brasileira?

Ao analisar o item Perfil Profissional verificamos que a Educação Física é considerada como uma área de conhecimento em formação e caracteriza-se por sua intervenção profissionalpedagógica e que o profissional, mediante referenciais científicos, filosóficos, estéticos e tecnológicos, objetiva a melhor qualidade das diferentes manifestações da cultura corporal de movimento; a partir de dois conceitos interligados: conhecimento da educação física e conhecimento pedagógico da educação física. Ou, este profissional/professor é definido como um "prestador de serviços" de atividade física, o qual deve considerar o dinamismo do mercado de trabalho e as necessidades sociais. Portanto, ser capaz de discutir, fundamentar e justificar a presença da Educação Física como componente curricular na escola. Nesta última frase, percebemos a não conviç̧ão dos professores universitários do reconhecimento do profissional de Educação Física escolar e, portanto, a ênfase neste sentido apresentada no PPC.

Observamos presente a tendência de uma formação acadêmica inicial voltada para uma atuação generalizada do profissional, mediante uma fundamentação teórica básica e que dê condições para habilitação e/ou especialização nos vários níveis de cada área (da iniciação ao alto nível), configurando-se num modelo tradicional e conservador da instituição universitária brasileira.

Constatamos que o perfil profissional é, também, por ora definido como um rol de atividades/competências/habilidades/aptidões:

preparação física, técnica e tática de equipes esportivas nos diferentes níveis, desde a iniciação esportiva até o esporte de alto nível; domínio das técnicas de intervenção na preparação atlética individual e/ou coletiva de equipes em diferentes níveis; conhecimento das técnicas administrativas básicas que permitam a supervisão e gerenciamento de equipes esportivas e de entidades de administração do esporte (clubes, ligas, federações e confederações), assim como nos diferentes níveis de organização governamental: municipal, estadual ou federal; organização de eventos esportivos em diferentes níveis; oferecimento de consultoria e assessoria relativa às suas áreas de especialização; assessoria, planejamento, execução e avaliação do componente curricular Educação Física na Educação Básica (Educação Infantil, Ensinos Fundamental e Médio).

No entanto, há PPC que procura inicialmente contextualizar historicamente e problematizar a área de Educação Física e a sociedade brasileira, enfatizando que não basta ao graduado dominar um conjunto de habilidades e técnicas relacionadas aos jogos, exercícios, esportes, às atividades lúdicas, às danças, mas, deve ser capaz de transformar conteúdos, visando solução de problemas e dilemas da realidade.

No item referente ao (s) Objetivo (s) do (s) Curso (s) constatamos, inicialmente, que nos PPC (s) são apresentados como Gerais e/ou Específicos. Porém, nem sempre apresentam clara distinção entre o que caracteriza o Objetivo Geral e os Específicos, ou seja, se misturam/confundem. Nos PPC (s) que não apresentam item específico referente aos Objetivos do Curso, notamos que são mencionados no Perfil Profissional do Egresso. Apenas um PPC de Licenciatura em Educação Física menciona claramente articulação com o Objetivo Geral dos Cursos de Licenciaturas da própria Instituição Universitária. Nesse sentido, verificamos processo inicial em busca de articulações com os PPI (s) e PDI (s). Observamos, ainda, uma nova proposta destacando atuação integrada e compartilhada envolvendo profissionais de outras áreas além da Educação Física. No entanto, a própria nomenclatura e objetivos do Curso chamaram a atenção, apresentando contradições, induzindo a pensar que se trata mais de outra formação.

Averiguamos que os Objetivos Gerais dos PPC (s) são formulados considerando-se que a Instituição Universitária e o Curso ao propiciarem uma sólida formação acadêmica e científica, os futuros profissionais estarão aptos a colaborarem na superação das atuais condições sociais nacionais (injustiças, discriminações, exclusão etc.) e, conseqüentemente, na construção de uma nova sociedade brasileira. Ou, consideram diretamente a formação específica do aluno futuro professor escolar, possibilitando-os a aquisição de conhecimentos, técnicas e habilidades, o desenvolvimento das competências, levando-o a ser um agente autônomo na construção de seu próprio conhecimento. Ou, definem a formação de 
professores e sua aptidão junto aos seus futuros alunos, qual seja a de destacar os direitos deles como cidadão, ou seja, de usufruir da cultura corporal de movimento.

Ao tratarem, especificamente, da formação de professores escolares, os objetivos enfatizam a realidade das escolas públicas, seus problemas e desafios e, portanto, visa-se a transformação da realidade brasileira. $E$, ao se pensar na atuação do profissional de Educação Física, especificam como objetivo o atendimento a população, atentando-se para uma melhor qualidade de vida. Relaciona as suas aptidões junto ao mercado, ou seja, estará apto a planejar, administrar, implantar, desenvolver programas de educação física, emitir pareceres, oferecer assessorias e consultorias nas áreas da saúde e educação e, ainda, diagnosticar, prescrever, orientar, supervisionar, controlar e avaliar projetos e programas de atividades físicas, de exercícios físicos, de atividades recreativas e esportivas, nas perspectivas da prevenção, promoção, proteção e reabilitação da saúde. Como objetivos de cursos, a prática profissional, alicerçada em conhecimentos científicos e em uma postura de pesquisa, o estímulo à iniciação científica, a reflexão e aprofundamento, evidenciaram-se nas duas habilitações em termos de graduação em Educação Física. No entanto, sabemos que é uma minoria de alunos de graduação participantes de grupos de pesquisas e com bolsa de iniciação científica, conforme dados da pesquisa intitulada "Contextos de formação inicial em cursos de educação física e medicina: uma análise comparativa dos dados de concluintes no ENADE/2004" (HUNGER et al., 2007).

O movimento humano apresentou-se denominado como o "instrumento" de atuação do profissional da Educação Física, estudado, pesquisado, compreendido, conforme as seguintes dimensões do conhecimento: Relação ser Humano - Sociedade; Biologia do Corpo Humano; Produção do Conhecimento Científico e Tecnológico; Culturais do Movimento Humano; Técnico-Instrumentais e; Didático-pedagógicas; respeitando-se as especificações da legislação federal (Resolução CNE/CES n. 7/2004). Portanto, tais cursos segmentam o movimento humano em conformidade com a classificação das grandes áreas da ciência, ou seja, biológicas, humanas e exatas. Podemos dizer, reproduzem o positivismo, a fragmentação do conhecimento tão criticada, mas não superada concretamente, em termos da docência universitária.

Os cursos de Licenciatura tratam da formação do professor escolar e a Graduação do profissional atuante nos campos de intervenção relacionados à saúde, lazer, esporte, reeducação motora, gestão, entre outros. Constatamos que perfis profissionais e objetivos são delimitados em termos dos campos de atuação profissional. E, ainda, ao contexto escolar é dado um olhar específico e aos demais (saúde, lazer, esporte etc.) uma visão generalista.

No que diz respeito à Estrutura Curricular, verificamos uma apresentação tradicional, ou seja, o elenco das disciplinas e respectivos créditos por semestre, denotando mais uma vez a fragmentação do conhecimento científico e profissional, ainda que observado um esforço em apresentar um conjunto de disciplinas em conformidade com os eixos temáticos sugeridos na própria legislação. Dos cursos investigados o porcentual de disciplinas caracterizadas na dimensão das Ciências Biológicas ainda é maior quando comparado às Ciências Humanas. No entanto, apesar de minoria, notamos novas disciplinas atentando-se para as questões de ética, meio ambiente e cultura, vislumbrando a possibilidade de uma formação direcionada para o pensamento e ações reflexivas.

\section{Considerações Finais}

Os PPC (s) apresentam uma avaliação (mesmo que superficial), bem como, um processo inicial de articulação com o (s) PPI (s) e PDI (s) das respectivas Universidades, respeitam as Novas Diretrizes Curriculares dos Cursos de Licenciatura e específicas da Educação Física, respondem as principais questões da literatura para se elaborar um PPC, mas finalizam com a chamada estrutura curricular, ou melhor, apresentam os fluxos curriculares, elencando-se as disciplinas e suas respectivas cargas horárias, ou seja, distante de uma perspectiva curricular temática.

Nesse sentido, questionamos se de fato os principais conceitos identificados nos PPC (s) investigados, como: interdisciplinaridade; indissociabilidade entre a teoria e prática; trabalho coletivo; compromisso social; ética pessoal e profissional; consciência crítica; transformações sociais; sociedade mais justa; democrática e auto-sustentável; auto-realização profissional; iniciação à pesquisa científica; atitudes reflexivas; inovadoras e democráticas; autonomia; coexistência pacífica; usufruto da cultura corporal de movimento; profissional competente; superação de preconceitos; aceitação da diversidade dos alunos; realidade social; novo ethos profissional; formação continuada; equipes multidisciplinares e articulação entre ensino, pesquisa e extensão, são concretizados. Não é difícil certificarmos que 
alunos e docentes universitários ao conceituarem corpo, movimento humano, educação física comprovam o pensar científico fragmentado e, assim, evidenciando a hipótese de que um PPC nem sempre é construído e/ou aplicado coletivamente. Portanto, desrespeitando um dos principais princípios ao se construir um PPC. É necessário consenso na aplicabilidade curricular com referência as concepções de sociedade e a profissão Educação Física.

Acreditamos que outra questão antiga e ainda não resolvida diz respeito a uma concepção generalista de formação na área de Educação Física (não só nessa área, trata-se de uma tendência da formação acadêmica universitária brasileira) e com ênfase de possibilidades num campo de atuação mercadológico abrangente. Advogamos na área de Educação Física a instituição da Residência nos moldes da Medicina, a qual se constitui:

numa modalidade de ensino de pós-graduação destinada a médicos, sob a forma de curso de especialização, funcionando em Instituições de Saúde, sob a orientação de profissionais médicos de elevada qualificação ética e profissional, sendo considerada o "padrão ouro" da especialização médica. ${ }^{3}$

Caso contrário, fadar-se-á a uma formação universitária inicial comumente dita como básica e dificilmente tal profissional será devidamente conceituado, reconhecido, valorizado e respeitado. Ou seja, manter-se-á o discurso de que "se sabe um pouco de tudo e não muito do pouco".

É preciso uma mudança de mentalidade e, conseqüente, intervenção curricular universitária! Para tanto, propomos uma ação conjunta das Instituições Públicas Estaduais e Federais do Estado de São Paulo na área de Educação Física, revendo os seus caminhos universitários e profissionais.

Enfim, de acordo com Rémond (1996), tal investigação dará à história do tempo presente um bom remédio contra as ilusões de ótica que a distância e o afastamento poderão gerar no que se refere à formação acadêmica inicial no campo da Educação Física, especificamente, no Estado de São Paulo.

\section{Referências}

ANDRÉ, M. E. D. A. Etnografia da prática escolar. Campinas, SP: Papirus, 1995.

\footnotetext{
${ }^{3}$ DECRETO No 80.281 DE 5 DE SETEMBRO DE 1977.
}

BRASIL. Congresso Nacional. Lei $\mathbf{n}^{\circ}$. 9.394, de 17 de dezembro de 1996.

BRASIL. Congresso Nacional. Lei $\mathbf{n}^{\circ}$. 9.696, de $1^{\circ}$ de setembro de 1998.

BRASIL. Conselho Estadual de Educação. Deliberação $n^{\circ}$. 7, de 19 de abril de 2000 .

BRASIL. Conselho Federal de Educação. Parecer $n^{\circ}$. 215, de 11 de março de 1987. Documenta n. 315, Brasília, março, 1987.

BRASIL. Conselho Federal de Educação. Resolução $\mathbf{n}^{\circ}$. 3, de 16 de junho de 1987. Diário Oficial n. 172, Brasília, 1987.

BRASIL. Conselho Nacional de Educação. Parecer CNE/CP n . 9, de 08 de maio de 2001.

BRASIL. Conselho Nacional de Educação. Parecer CNE/CP $\mathbf{n}^{\circ}$. 27, de 2 de outubro de 2001.

BRASIL. Conselho Nacional de Educação. Parecer CNE/CP ${ }^{\circ} .28$, de 2 de outubro de 2001.

BRASIL. Conselho Nacional de Educação. Resolução CNE/CP $\mathbf{n}^{\circ}$. 1, de 18 e fevereiro de 2002.

BRASIL. Conselho Nacional de Educação. Resolução CNE/CP n ${ }^{\circ}$. 2, de 19 de fevereiro de 2002.

BRASIL. Conselho Nacional de Educação. Parecer CNE/CSE $\mathbf{n}^{\circ}$. 58, de 18 de fevereiro de 2004.

BRASIL. Conselho Nacional de Educação. Resolução CNE/CSE $n^{\circ}$. 7, de 31 de março de 2004.

BRASIL. Conselho Nacional de Saúde.

Resolução n. 218, de 06 de março de 1997.

BRASIL. Ministério da Educação. Comissão Nacional de Avaliação da Educação Superior. Instrumento de avaliação de cursos de graduação. Brasília: Instituto Nacional de Estudos e Pesquisas Educacionais Anísio Teixeira, 2006.

BRASIL. Decreto $\mathbf{n}^{\circ} \mathbf{8 0 . 2 8 1}$, de 5 de setembro de 1977.

CHARTIER, R. Pensar o tempo presente, a visão do historiador modernista. In: AMADO, J.; FERREIRA, M. M. (orgs.). Usos e abusos da história oral. Rio de Janeiro: Fundação Getúlio Vargas, 1996. cap. 17, p. 215-218. 
Conselho Regional de Educação Física. CREF4/SP. Instituições de Ensino Superior. Disponível em:

<http://www.crefsp.org.br/instituicoesEnsinoSuper ior.asp>. Acesso em: 25 jan. 2009.

DEMO, P. O conhecimento moderno - sobre ética e intervenção do conhecimento. Petrópolis: Vozes, 1997.

FOUCAULT, M. L'Archéologie du savoir. Gallimard, Paris, 1969.

\section{GADOTTI, M. Perspectivas atuais da}

educação. Porto Alegre: Artes Médicas Sul, 2000.

GADOTTI, M. Projeto político-pedagógico da escola: fundamentos para a sua realização. In: GADOTTI, M.; ROMÃO, J. E. (orgs.). Autonomia da escola: princípios e propostas. 4 ed. São Paulo: Cortez; Instituto Paulo Freire, 2001. p. 3341.

HUNGER, D. et al. Contextos de formação inicial em cursos de educação física e medicina: uma analise comparativa dos dados de concluintes no ENADE/2004. In: V Congresso Internacional de Educação Física e Motricidade Humana e XI Simpósio Paulista de Educação Física, V, 2007, Rio Claro. Anais... Rio Claro: Motriz, v. 13, n. 2 (Supl.1), 2007. p. 91.

LE GOFF, J. História e memória. Campinas/SP: Editora da UNICAMP, 1992.

PADILHA, P. R. Planejamento dialógico: como construir o projeto político-pedagógico da escola. 4 ed. São Paulo: Cortez; Instituto Paulo Freire, 2003.

PEREIRA, E. M. A. Subsídios para a Elaboração do Projeto Pedagógico. Disponível em:

<http://www.prg.unicamp.br/projeto pedagogico.h tml>. Acesso em: 09 dez. 2008.

PIMENTA, S. G. (org.) Saberes pedagógicos e atividade docente. $3^{a}$ ed. São Paulo: Cortez, 2002.

RAMPAZZO, L. Metodologia científica: para alunos dos cursos de graduação e pósgraduação. Lorena: Editora Estiliano, 1998.

RÉMOND, R. Pensar o tempo presente - algumas questões de alcance geral à guisa de introdução. In: AMADO, J.; FERREIRA, M. M. (orgs.). Usos e abusos da história oral. Rio de Janeiro: Fundação Getúlio Vargas, 1996. cap. 15, p. 203209.
SOBRINHO, J. D. Avaliação da Educação

Superior. Petrópolis, RJ: Vozes, 2000.

VASCONCELLOS, C. S. Coordenação do trabalho pedagógico: do projeto políticopedagógico ao cotidiano da sala de aula. 5 ed. São Paulo: Libertad, 2004a.

VASCONCELLOS, C. S. Planejamento: projeto de ensino-aprendizagem e projeto políticopedagógico - elementos metodológicos para elaboração e realização. 12 ed. São Paulo: Libertad, 2004b.

VEIGA, I. P. A. Perspectivas para reflexão em torno do projeto político-pedagógico. In: VEIGA, I. P. A.; RESENDE, L. M. G. (orgs). Escola: espaço do projeto político-pedagógico. Campinas: Papirus, 2003.

WIKIPEDIA. Residência Médica. Disponível em: $<$ http://pt.wikipedia.org/wiki/Residência médica $>$. Acesso em: 28 jan. 2009.

Esse artigo foi apresentado em Sessão Temática no VI Congresso Internacional de Educação Física e Motricidade Humana e XII Simpósio Paulista de Educação Física, realizado pelo Departamento de Educação Física do IB/UNESP Rio Claro, SP de 30/4 a 03/5 de 2009.

\author{
Endereço: \\ Dagmar Hunger \\ Rua 13 de Maio, n. 7 -27 - Edifício Bandeirantes \\ - Apto. A1 - 12 \\ Bauru SP Brasil \\ 17015-270 \\ Telefax: (14) 3103-6082 \\ e-mail: dag@fc.unesp.br
}

Recebido em: 10 de fevereiro de 2009.

Aceito em: 03 de abril de 2009.

Motriz. Revista de Educação Física. UNESP, Rio Claro, SP, Brasil - elSSN: 1980-6574 - está licenciada sob Licenca Creative Commons 